\title{
Erratum to: Predicting the Amplitude of a Solar Cycle using the North -South Asymmetry in the Previous Cycle: II. An Improved Prediction for Solar Cycle 24
}

\section{J. Javaraiah}

Received: 16 July 2010 / Accepted: 21 July 2010 / Published online: 3 August 2010

(C) Springer Science+Business Media B.V. 2010

Erratum to: Solar Phys. 252:(2008), 419-439

DOI 10.1007/s11207-008-9269-6

The values of the epochs of minima $\left(T_{\mathrm{m}}\right)$ and maxima $\left(T_{\mathrm{M}}\right)$ of the cycles as well as $T_{\mathrm{m}}^{*}$ and $T_{\mathrm{M}}^{*}$, which are given in the columns 2, 4, 6, and 9 of Table 1, seem to be confusing. For example, the minimum epoch 1878.9 and the maximum epoch 1883.9 of cycle 12 are sometime mistaken as November 1879 and November 1884, respectively. These epochs actually represent November 1878 and November 1883, respectively. The $T_{\mathrm{m}}^{*}$ and $T_{\mathrm{M}}^{*}$ should also be interpreted this way. For example, the values 1877.55-1881.05 and 1884.90-1885.65 of $T_{\mathrm{m}}^{*}$ and $T_{\mathrm{M}}^{*}$ of cycle 12 represent July 1877-January 1881 and November 1884-August 1885 , respectively.

I apologize for this late clarification.

The online version of the original article can be found under doi:10.1007/s11207-008-9269-6.

J. Javaraiah ( $\varangle)$

Indian Institute of Astrophysics, Bangalore 560 034, India

e-mail: jj@iiap.res.in 